\title{
Spanish E-Consumer Segmentation and Positioning in Virtual Supermarkets Sector
}

\author{
Eduard Cristóbal \\ Faculty of Law and Economics, University of Lleida \\ C/ Jaume II, 73 Campus de Cappont, 25001, Lleida, Spain \\ Tel: 34-973-703-3323 E-mail: cfeduard@aegern.udl.cat
}

Frederic Marimon

Faculty of Economics, International University of Catalonia

Immaculada, 22, 08017 Barcelona, Spain

E-mail: fmarimon@cir.uic.es

Natalia Daries

Open University of Catalonia (UOC)

Av. Tibidabo 39-43, 08035 Barcelona, Spain

Yolanda Montagut

Faculty of Law and Economics, University of Lleida

C/ Jaume II, 73 Campus de Cappont, 25001, Lleida, Spain

E-mail: ymontegut@aegern.udl.cat

Received: November 9, $2010 \quad$ Accepted: December 12, $2010 \quad$ doi:10.5539/ijms.v3n2p16

\begin{abstract}
This article analyses different factors that influence the purchasing behaviour of online supermarket customers. These factors are related to both the appearance of the website as well as the processes that take place when making the purchase. Based on these analyses, the various groups of consumers with homogenous behaviour are studied and positioned according to their attitudes. The analysis also allows the quality of the service offered by this kind of establishment to be defined, as well as the main dimensions in which it develops. In the conclusions, factors which should influence the manager of an online supermarket to improve the quality of its service are given.
\end{abstract}

Keywords: Virtual supermarket, Segmentation, Internet, E-commerce, Marketing, Quality, Positioning

\section{Introduction}

The fact that Internet is becoming an important business channel and a way of achieving clients is a reality. In June 2010, it was calculated that there were 1,966.5 million users, representing $28.7 \%$ of the world population (Internet World Stats, 2010), of which 29 million were Spanish and generated a business volume of 5,752 million euros in 2009 in our country, according to the CMT (Telecommunications Market Committee) (2010). If we focus on the food sector, according to a study by Red.es (2009), 19.3\% of the population have carried out some kind of purchase during 2008 in the food and bazaar category (with a growth of almost 9 points on the previous year).

Therefore, we observe a significant growth in purchasing of this kind of product. The food product distribution sector in our country has not been alien to this reality and to the possibilities offered by the Internet as a channel 
of commercialisation. The advances in the information and communication technology sector in general and in the Internet in particular have significantly influenced the management of commercial surface areas (Martínez et al., 2008). Of this, we should highlight the continuous incorporation into the network of the main distribution channels in Spain, from department stores such as El Corte Inglés, hypermarkets such as Carrefour or Eroski to supermarkets such as Condis or Plusfresc (which is the supermarket chain which is the object of this study).

The Internet allows them to reach new markets and new consumers. However, it is not enough just to reach them, they need to be retained and loyalty needs to be encouraged. Nevertheless, not all online companies are aware of this. A report carried out by comScore marketing research company for PayPal (2008) confirmed that $60 \%$ of internet users who choose something to buy, do not complete the purchase process. What is the reason for this situation? Initially, we could assume that the main reasons are of a technical nature (e.g. deficiencies in the communication networks, connection problems); or a lack of experience in the use of the Internet by the consumers. However, other factors could be influencing this behaviour of the consumer, among which we should highlight those related to errors in the transaction, the information required to complete the purchasing process or the ease-of-use of the website.

Acquiring online consumers is difficult and costly (Van Riel et al., 2001). Consumers can easily access and compare the services offered by various online businesses. A good quality service must be offered which gives satisfaction and creates loyalty. Numerous studies demonstrate that the higher the perceived quality on the website is, the higher the levels of profitability are (Hoffman et al., 1995; Lohse and Spiller, 1998, 1999; Swaminathan et al., 1999; Yang et al., 2003 among others). Nevertheless, these studies are generally focused on factors of graphic design and perceived usability of the website (Li et al., 1999; Mandel and Johnson, 1999; Menon and Khan, 1997).

In addition, there is a large group of pieces of work that show the relationship between the perceived value for money and satisfaction or loyalty (Srinivasan et al., 2002; Anderson and Srinivasan, 2003; Ribbink et al., 2004; Sigala and Sakellaridis, 2004; Boshoff, 2007; Cristóbal and Marimon, 2007; Huang, 2008; Fuentes-Blasco et al., 2010; Lin, 2010; Marimon et al., 2010). Specifically, Srinivasan et al. (2002) define loyalty in the online environment as a favourable attitude of the customer towards its supplier that leads him or her to a behaviour of re-purchasing. Sigala and Sakellaridis (2004) coincide with them stating that quality in E-commerce plays an important role in explaining loyalty. Huang (2008) also makes a review of the literature and finds agreement between academics when stating that quality is a prerequisite of loyalty. More recently, Fuentes-Blasco et al. (2010) find that greater levels of quality mean an increase in benefits for the client; this means that the company is perceived as being more attractive and finally results in a higher degree of retaining these clients. Therefore, we consider it to be necessary to complement these contributions by studying which aspects of the service given by a website — beyond that of an attractive, user-friendly interface - determine the quality perceived by the consumer and therefore his or her behaviour.

The main objective of this piece of research is to identify the relevant factors in the decision to purchase when designing a virtual supermarket and to study and classify the behaviour of the client of this type of establishment according to his or her attitudes towards these factors. To achieve these objectives, the work is structured in two parts. The first part, with a theoretical content, contains a review of the literature about virtual merchandising factors and their application to online stores, as well as the studies carried out to study the behaviour and classification of online consumers. In the second part, through an empirical study of the users of a virtual supermarket, an analysis of segmentation is carried out with the aim of identifying and positioning the segments of consumers with different purchasing behaviour.

\section{The Virtual Store}

When talking about a virtual establishment, we could be imagining a shop in the street, but with the peculiarity that it is found on the Internet. We would not be very far wrong, but a series of comments need to be made to give this commerce the status of virtual, a meaning which would be equivalent to those proposed by other authors, such as E-store, online store, web store, virtual store, E-catalogue and many others.

Some authors claim that to consider a website as a virtual establishment, it should fulfil the only requirement of making it possible to purchase by means of any online system and that it covers everything from the most complex order forms to the simplest e-mail, committing itself to deliver the product to the address indicated by the customer. In a summarised way, we could claim that the functions of a real shop are: a) To inform and to sell; b) To permit orders to be placed; c) To charge; d) To deliver the product; e) To offer an after-sales service. All these functions can and should be reflected in the services offered by a virtual establishment and on the Internet the first function, that of informing and selling, is called virtual merchandising (Cristóbal, 2006). 
Virtual merchandising, like traditional merchandising, is concerned with the decoration of the place, the presentation of the products, their rotation and the profitability of the establishment (see table 1). All these factors influence the behaviour of the online customer.

The virtual equivalent of the shop window would be the design, the graphics and the communication. These functions are being constantly improved and updated with the incorporation of multimedia communication. Nevertheless, there are still some limitations that prevent us from putting into practice some traditional merchandising techniques, such as the fact that the viewing of the virtual establishment is two-dimensional, therefore some information and other stimuli that could constitute points of reference for decision-making are lost (Rodríguez, 2008).

Take table 1.

To finish this part, we can confirm that studies focusing on the distribution of food products are not very frequent. At a Spanish level, we find the work by Celestino and Borja (2005) in which they study the main online establishments in Spain, focusing on the analysis of the main advantages and inconveniences (see table 2), both for companies as well as for consumers, of the use of E-commerce for purchasing food products on the Internet. These authors focused both on the companies as well as the consumers on exposing the advantages of this media. The online channel offers distribution companies greater presence at a geographical level and the possibility of expanding their demand as a constant increase in the number of users with Internet access is being observed. At the same time, the interactive nature of the Internet allows for information to be compiled and to be used to personalise the content and the offers of the virtual establishment. In certain sectors, E-commerce can involve the removal of business intermediaries and the reduction of costs, above all if we are talking about products that can be digitalised. In this study, we comment about whether supermarkets using Internet as an additional sales channel can generate extra synergies or advantages for the business by using traditional and digital channels at the same time.

At a consumer level, one of the main advantages is the access to a large amount of information that allows them to have greater possibilities of choice without taking into account their geographical location. Therefore, the Internet provides online clients with greater convenience and a saving in terms of time and effort when making their purchases. Finally, we should highlight the fact that the purchase of certain types of products by this means can offer a greater level of freshness of food products as their manipulation and the time during which they are displayed to the public is reduced (Celestino and Borja, 2005).

Take table 2 .

On the other hand, and following a highly differentiated line of study, that of the study of the dimensionality and evaluation of the quality of the service given by a virtual store, we should highlight the work carried out by Marimon et al. (2010) in which they extract the main factors of quality and their relationship with satisfaction and loyalty applied to an online supermarket. Quader and Quader (2008) examine the strategic affects of the use of E-commerce by traditional supermarkets. In turn, Martínez et al. (2008) carry out a comparative study of the websites of supermarkets focusing on aspects such as the price differences, the transport costs, the security of the purchasing process, the available methods of payment, user-friendly navigation, etc. After carrying out this review on work focused on distribution, we believe that our investigation could offer a different focus as it is focused on the study of the behaviour of virtual supermarket customers and their classification.

\section{The Segmentation of the E-Consumer}

As mentioned in the first part, the number of Internet users and therefore the number of E-consumers is reaching significant proportions. This situation means that it is becoming increasingly more essential for companies to be present on the Internet and virtual supermarkets cannot be left to one side. It is also true that not all Internet users have the same behaviour, not only in the use they make of the Internet but also in their purchasing behaviour. Following this line, there are various studies that show that not all online purchasers use and value the Internet in the same way, therefore making it recommendable to develop differentiated commercial strategies for each kind of client (Bigné et al., 2004; Flavián and Gurrea, 2004; Keng, Tang and Ghose, 2003; Rohm and Swaminathan, 2004; Swinyard and Smith, 2003).

A piece of work done by Ruiz and Sanz (2006) offers a complete review of the segmentation studies carried out in virtual environments and applied to different sectors. In a preliminary work, the same authors Ruiz and Sanz (2005) identified the profile of the distance purchaser in Spain, showing the relevant variables in the purchasing decision, extracting four segments based on socio-demographic variables and on the frequency of access to the Internet. 
In a piece of research carried out in the sector of electronic products by Donthu and García (1999), groups of individuals were distinguished according to socio-demographic variables (age and income) and attitude variables (convenience, aversion to risk, search behaviour, attitude towards advertising and towards distance purchasing). In another piece of work within the same sector, carried out by Vrechopoulos, Siomkos and Doudikis (2001), they used demographic, behavioural and attitude characteristics to classify different segments of E-consumers in Greece. These authors distinguished between current purchasers and potential purchasers interested in the use of the Internet as a purchasing channel and described the profile and behaviour of both groups.

In a piece of work carried out by Brown, Pope and Boges (2003), they obtained six groups of consumers after carrying out a cluster analysis, taking as a point of reference the intentions of the individual in a virtual environment, intentions either to purchase or to generally view the site. A study carried out by Rohm and Swaminathan (2004) identified four different profiles of online purchasers according to their motivations: comfort and convenience (convenience shoppers), extent of information and assortment (variety seekers), convenience and assortment (balanced buyers) and immediate possession of the products and services and social interaction (store-oriented shoppers).

We can see that the main variables which, according to the studies carried out, determine the decision to purchase of this kind of client are the socio-demographic variables or the attitude variables or the reasons for purchasing, such as comfort, convenience, the extent of information or assortment or immediate possession of the products.

In this part, we could mention the study carried out by Keng, Tang and Ghose (2003) in which a segmentation of consumers was made according to their demographic characteristics, experience as users and purchasing behaviour on the Internet. The interest of this piece of work comes from the fact that in it, a series of factors of a varied kind are integrated in which demographic and behavioural characteristics of online consumers are combined, offering an overall perspective. Our piece of research aims to be found within the line of integrating a variety of factors of a different nature with the purpose of explaining the behaviour of online consumers.

This piece of research defines purchasers, with regard to demographic variables, such as young people in the 20 to 29 year age segment, possibly due to the fact that the image and the products offered do not usually fit in with the lifestyle of older consumers. These results are similar to those of the present piece of work. The main characteristics of the six segments obtained by Keng, Tang and Ghose (2003) are the following: 1) On-off shoppers: They use Internet as an information channel but make their purchases in traditional channels. They are expert surfers. Young, single people of both sexes; 2) Comparison shoppers: They compare the characteristics of the products, prices and brands before making their purchases. They look for offers. Young, single men; 3) Traditional shoppers: They mainly compare in traditional shops. They have not much experience in surfing. Men aged over 40; 4) Dual shoppers: They only use the Internet as an information channel. They are expert surfers. They use the Internet to compare brands and products. Young, single men: 5) E-laggards: They do not use the Internet as an information channel. They have virtually no experience as Internet users. Women aged over 35; 6) Information surfers: They have high experience in purchasing. They look for offers and they like advertisements. They have a lot of experience in surfing. Married men aged over 30.

Finally, and based on the online supermarket sector, we find the research carried out by Martínez et al. (2008) in which a segmentation is made, not of the consumers but of the different establishments in accordance with their position with regard to E-commerce.

\section{Objectives and Methodology}

As previously mentioned, this study has two main objectives:

To investigate which elements are important when designing a virtual supermarket.

To study and classify the behaviour of the client of an online supermarket according to his or her attitudes towards these factors.

The methodology used to achieve this double objective was carrying out an empirical study on a sample of online supermarket clients, on whom a survey was carried out with the aim of highlighting the main factors of the virtual establishment that they valued most for the process of purchasing food products on the Internet.

To deal with these objectives, we sought the collaboration of a chain of supermarkets with presence on the Internet: the Plusfresc supermarket chain which operates in Lleida. The company has more than 75 years' history and currently has 69 establishments and more than 850 employees. The company has become characterised by having an innovative character and being customer oriented. In 1996, it introduced its loyalty card Plusi, the first customer loyalty card on the Catalan market. In 1998, Plusfresc won the Global Electronic Marketing Award in 
the United States for the best electronic marketing programme presented by a non-American company. In 2001, it set up its virtual establishment http://www.Plusfresh.com.

During December 2007 and January 2008, a web-based survey was carried out, by placing a banner on the supermarket website to redirect customers to the questionnaire. To access the survey, they had to provide their customer number. With this information, we made sure that they were in fact Internet users who had access the supermarket's website and had interacted with it. At the same time, it enabled us to carry out later controls to verify the truthfulness of the responses.

To design the questionnaire, following Marimon et al. (2010), the basis was the E-S-Qual instrument developed by Parasuraman et al. (2005). The scale was adapted for the particular context of the online supermarket. The work of Parasuraman et al. (2005) was also taken as a reference for the questions on the overall assessment and to compile information about the recovery by the supermarket in cases in which the client detected some kind of anomaly or problem in the service (for this last case, the E-Recs-Qual scale was used). Therefore, the survey was divided into three parts. The first section of items was aimed at assessing the perception of the quality of the service offered by the virtual supermarket in general. The second section was based on assessing the response of the company in the case that the user had had any kind of problem or incident. The third section incorporated a series of questions with the aim of assessing the satisfaction with the purchasing process, as well as the intention to buy from them again. 159 valid responses were obtained, meaning a response level of $40 \%$, as the number of online purchasers was 413 according to the database provided by the company. To stimulate the response, customers who responded to the survey were offered a gift; this incentive consisted of adding a bottle of wine to the next purchase they made. The size of the sample was sufficient to be able to extract robust conclusions. Manfreda et al. (2008) compared the samples used in 45 studies based on web-based surveys. The variety of sizes used varies from a minimum of 28 to a maximum of 2,979 . The mode is 115 responses. At the same time, the level of response is totally in keeping with these studies. Manfreda et al. (2008) found an average response rate of $32 \%$ with a standard deviation of $17 \%$.

The profile of the consumers questioned is the following: experienced, loyal internet user $(74.4 \%$ have been clients for more than a year); they access the website with certain frequency ( $44.5 \%$ access it several times a month); more than half of them have university studies (55.5\%); most of them are women (76.8\%); and finally it should be said that the users are young (three quarters of the sample were aged under 45).

Based on the results obtained, we proceeded to carry out a multivariate analysis to determine the segmentation of the market and to apply the factor analysis method. This method provides us with the relevant information of the initially observed data and determines the main factors that allow us to get to know the most valued characteristics of online stores. Based on these results, we group the Internet users into different collectives to define their behaviour.

\section{Segmentation of Online Supermarket Clients}

With the aim of distributing the people surveyed — virtual supermarket clients - into homogenous segments, we proceeded to carry out a K-means analysis. In order to do this, we started with the question in the survey which requested an assessment (marks from 1 to 5) of the overall quality of the service offered by the virtual supermarket. Once the segmentation had been made, a factor analysis was applied to the series of items shown in table 4 , with the aim of assessing a virtual supermarket. Finally, the segments were positioned with regard to the factors obtained in the factor analysis.

The various items of this questionnaire arose from the E-S-Qual model of Parasuraman et al. (2005) to measure the perceived quality of the service offered by a virtual establishment through a multidimensional analysis. The structure of the E-S-Qual scale was followed, which was made up of four dimensions: Efficiency (ease and speed to access and use the website); Availability of the system (correct technical functioning of the web); Reliability (level of compliance with the delivery deadlines and availability of the product); and Privacy (level that indicates the security of the website and the level of protection of users' data).

At the same time, a preliminary hierarchical analysis was carried out that indicated that there were two naturally constituted groups (see figure 1). We then proceeded with the K-means analysis, forcing the extraction of two segments. As a result of this, two segments with different sizes were obtained: one large group which brought together two thirds of the sample with 117 individuals and a smaller group with 42 individuals. The centres of the two conglomerates finally obtained gave a figure of 3.86 for the first segment and 5 for the second segment. These values show the high assessment of the quality of the service given by this virtual supermarket in both groups. At the same time an ANOVA analysis of the conglomerates was made which reinforces the results obtained, giving the Snedecor F a value of 453.96 with a significance of 0.0 . 


\section{Take figure 1}

An initial analysis of a non-parametric kind enabled us to detect differences in behaviour between these two groups. In fact, the Wilcoxon Mann-Whitney analysis (assuming that the variables do not follow a normal distribution) of these three variables, on grouping them according to the two segments found, shows significant differences, with a significance of 0.05 with regard to the value perceived and satisfaction. Nevertheless, the two segments do not show differentiated behaviour on assessing the response of the supermarket in the case of any problem (see table 3).

\section{Take table 3}

Both segments show a very high mark for service received with marks of above 4 , although it is the second segment that represents a greater valuation of the service given by this virtual supermarket. The second segment also shows greater satisfaction. Figure 2 shows the average marks obtained. The scale of measure is between 1 and 5. It can be seen that although the behaviour is differentiated, the marks are high. It is also interesting to see that the assessment to the response of the supermarket when there has been a problem is similar (with no significant differentiation at level 0.05 ).

Take figure 2

Below we describe each of the segments analysed:

\section{Segment 1}

As we have already commented above, this is the most demanding group of users, as it shows an average valuation that is inferior to that of the other segment. With regard to the first block of general service offered, this group values aspects related to the usability of the website and trust very positively. With regard to the latter attribute, these Internet users have valued items related to compliance with delivery deadlines, offers promised and finally, data protection.

These results are not very different from other applied studies. According to a study carried out by Red.es (2009) more than $95 \%$ of the individuals who had made purchases on the Internet during 2008 declared they were satisfied with their purchases, while only $4.6 \%$ of purchasers stated that their online purchases had not met their expectations. On the other hand, the good assessment of aspects related to compliance with promises and data protection is a positive piece of information, as according to this same study, lack of trust with regard to providing personal data or bank information is the second highest reason given by people for not purchasing in a virtual environment.

Aspects that are valued lower in this part were elements related to the availability of the product, the information provided and the speed of navigation on the website. This is particularly worrying as they are key aspects in the management of a virtual environment (Cristóbal and Marimon, 2007).

In the case of problems arising, these users assessed factors such as the possibility of contacting the company by telephone and the possibility of returning the product in an easy way as being highly positive. On the other hand, they consider that the company does not sufficiently compensate for the delay in an order or problems that arise.

With regard to factors of the website as a supermarket, they value the convenience of being able to purchase online but they complain about the prices of the products available on the website. They are fairly satisfied with the purchasing experience, as they consider it very likely that they will make more purchases on the website in the forthcoming months, although this may not be their first option.

If we compare them with the users in the second segment, the members of this group frequent the establishment to a lesser degree: the number of yearly online orders is lower (9.35 as opposed to 14.34) and at the same time the number of yearly orders in the conventional supermarket is also lower (72.17 as opposed to 82.75$)$. On the other hand, it was seen that the average total of the online purchases similar: $€ 113.63$ in the first segment as opposed to $€ 107.06$ for the second segment.

Having analysed the different perceptions of this collective, we will look in depth at its profile and its online behaviour.

We are talking about the most numerous segment, as it represents 117 individuals or $73.5 \%$ of the sample. With regard to age, it is very similar to the other segment although it is slightly younger (30\% are aged under 35$)$. Also, in both segments, women are notable, although in this case, the presence of men doubles that of the second segment. We should remember that we are talking about a website on which frequent food purchases for the home are being made; therefore it is not unusual that in both segments the presence of women should exceed $70 \%$. (73.5\% in segment 1 and $85.7 \%$ in segment 2$)$. According to a study by TNS market research Company 
(2008) one of every 5 shopping baskets is filled by men. Men were responsible for $19 \%$ of the purchases in 2008 as opposed to $10 \%$ in 2000 .

The level of educational qualifications is high, as almost $54 \%$ of those questioned stated that they have a university education, however it is also the collective in which there is greatest presence of people without qualifications or with just primary school studies. The fact that both groups contain a higher level of educational qualifications collaborates the results of research carried out into Internet users. Following these lines, the study on e-commerce carried out by Red.es (2009) shows that $37 \%$ of online purchasers have completed higher-level studies.

With regard to their online behaviour, we can confirm that they make up a group of experienced users $(74.4 \%$ have been clients for more than three years) and intense users as $23.9 \%$ connect several times a month to the online supermarket.

The individuals who make up this segment could be called: Demanding young people concerned about the availability of the product.

Segment 2:

Unlike the first segment, this group has a higher perception of the service offered by this virtual supermarket, both with regard to service in general as well as dealing with incidents if there are any problems. It also shows a level of satisfaction and of intention to purchase again higher than the first group of users.

This group positively valued factors such as the speed of the purchase, availability and the correct functioning of the online store and, in the same way as segment 1 , compliance with the delivery deadlines. These factors are closely related to the concept of convenience, a concept that is highlighted as one of the main reasons for buying on the Internet, as shown in this study carried out by Red.es (2009) on e-commerce. On the other hand, this collective valued below the average factors such as the immediate nature of the download and functioning of the online supermarket website and, coinciding with the first segment, the availability of the product in the assortment found in the online version.

What the users of this segment valued most positively was the fact that the company takes responsibility for returned products. On the other hand, they are more concerned about aspects related to compensation in the case of delay in delivering the shopping and about problems that may arise during the purchasing process (above all, if the connection fails before completing).

Like the first segment, and with regard to the possibility of being able to purchase from this supermarket on the Internet, they positively value the convenience of online shopping but they also complain about the prices of the products available on the website. As previously mentioned, this group is generally more satisfied than the first group and gives high marks to the possibility of being able to purchase from the website in forthcoming months as well as recommending the website if they are asked about it.

As indicated in the description of the first segment, the members of this group frequent the establishment more assiduously, as the number of yearly orders both from the online supermarket as well as in the conventional one are greater, however it is observed that the average total of the online purchase is lower. They purchase more often but they spend less on each purchase.

Finally, we will proceed to describe the individual that makes up this segment. We are talking about a young client, however in this segment the average age is slightly older than in the first segment. It is the segment with most women and with university studies. As far as use of the website is concerned, they are habitual clients, with experience and frequency of visits, as more than $21 \%$ of them visit the online supermarket once or several times a week.

This segment could be given the name: Satisfied clients who are seeking convenience, concerned by the function of the website and who are looking for fast, easy navigation

\section{Positioning of Online Supermarket Purchasers}

Once the two segments have been identified and based on the attributes to be valued in a virtual supermarket, a factor analysis of the main components was applied. This method reduces the set of variables correlated to a lower number of components that are intercorrelated with each other. A series of quantitative levels were obtained as a result. Among the most important ones, we would highlight own values, communalities and the factor matrix. The own values indicate the percentage of variance of the original variables that explain each of the components, the communality indicates the percentage of variance of each variable that is explained by the components and the factor matrix shows the correlation between the components of the variables. 
Take table 4

The correlations calculated between the variables of this analysis show a certain communality in their explanatory capacity. Two tests were carried out on the matrix of correlations: Bartlett's test of sphericity and the Kaiser-Meyer-Olkin (KMO) measure.

The Bartlett statistic, that takes the value of $\chi 2=1,702.059$ with a level of critical significance of 0.000 , allows one to reject the null hypothesis of non-correlation between the variables observed. The Bartlett test confirms the existence of linear dependence between variables and justifies the continuity of the procedure. Therefore, it is relevant to apply the factor analysis.

An exploratory factor analysis was carried out and four factors or components were obtained (see table 4). To prepare it, the Kaiser criterion was used in such a way that only the factors that had their own values that were greater than the unit were preserved. These four factors retain $60.8 \%$ of the initial dispersion, which represents the correct proportions if we take into account the fact that each of the new components provides independent information which is therefore not repeated.

With the rotated component matrix (Varimax rotation method) the weighting of each factor was obtained in each of the variables and in view of the fact that the factors are orthogonal, the factor loads are coefficients of correlation between variables and factors. Each factor has a high correlation with one group of variables and a low correlation with the rest, thus obtaining a more suitable interpretation of the initial factors.

The factors that resulted from the analysis were assigned a label and a rating or grade. This rating is the arithmetical average of the items of which it is made up (see table 4). Each factor has corresponding variables with high saturations (they appear in bold in the above rotated component matrix).

FACTOR 1 Efficiency: this is positively related to characteristics such as the organisation of the website, the layout of the information, the speed of the purchasing process, the ease of use or the ease of finding products (Average mark: 4.33).

FACTOR 2 Availability of the system: this is defined by aspects related to the functioning of the website, if it downloads and functions immediately, if it does not block or the system does not block or if the purchasing process is available (Average mark: 4.25).

FACTOR 3 Reliability: this is positively related to the delivery process of the products. That they are delivered when envisaged and in correct condition, that the products are available and that the timeslots for delivery are suitable. (Average mark: 4.22).

FACTOR 4 Privacy: this is positively related to the protection of information, both with regard to credit card details as well as the purchasing behaviour of the user, as well as the fact that this information is not shared with other websites. (Average mark: 4.28).

Take figure 3

The four factors are rated with more than a 4, which allows us to conclude that the satisfaction of the purchasing experience in a virtual supermarket has been positive. In the four dimensions, segment one is always more demanding. A further Wilcoxon Mann-Whitney analysis of these four dimensions, on grouping according to the two segments found, (table 5) showed that these differences between segments are all significant at a level of significance of 0.05 . The two segments value the four dimensions in a different way.

Take table 5

\section{Positioning Maps of the Resulting Segments}

We finally proceed to situate the two segments obtained with regard to the four factor axes. One can observe which characteristics of an online supermarket are most highly valued by the different segments, in other words, its positioning with regard to the various factors (see figures 4, 5 and 6).

On observing these six charts, it is surprising to see that the segments always occupy the same relative positions. The second segment is the group of clients that most highly value the aspects related to the four factors; they are found in the upper right-hand side of the diagrams. On the other hand, it can be seen that the individuals in the first segment pay less value to different attributes related to the four factors and to those found in the lower left-hand side of the diagrams.

Take figure 4

As previously commented, the clients of segment 1 are those that show less satisfaction with the service offered by the virtual supermarket. 
It can be seen in figure 4, how the second segment stands out both with regard to "Reliability" as well as "Efficiency". They are Internet users who have had a positive experience with regard to their visits to the online supermarket, where they have found a well-organised, easy-to-use website, where they have been able to carry out their purchase process quickly and have had their products delivered without incidents.

Take figure 5

The set of figures observed show that the first segment is dissatisfied with regard to the four factors analysed. Therefore, it would be recommendable for the online company to improve these aspects to maintain the clients of this segment which, at that time, was the most numerous.

Take figure 6

\section{Conclusions}

In the first place, it should be said that the quality of the service offered by a virtual supermarket to the clients questioned is satisfactory. The four factors that determine the quality of the service (efficiency, availability of the system, reliability and privacy) have obtained marks of over 4 on a scale of 1 to 5 , in which 3 is the central value.

Nevertheless this data is not sufficient. In view of the results, we could state that the management of a virtual supermarket carried out as if it were a mere extension of a traditional shop could be an important reason for commercial failure. All E-commerce initiatives must adapt to the reality of the medium as well as to its users.

On the other hand, if we analyse the existing literature about studies of segmentation in the field of E-commerce, we are able to frame this piece of research into studies which use variables of different natures in an integrated way to be able to offer more complete, overall results. The analysis of segmentation was based on socio-demographic variables, the experience of users, the length of time they had been clients, the level of spending in the establishment, as well as attitude and motivational variables. We can observe that the main variables which, according to this piece of research, determine the decision to purchase in this type of establishment are related to the ease of use of the website, their trust in it and the convenience in the purchasing, as described below.

From the results obtained, we can extract a series of reflections:

The individuals of the two highlighted segments show differentiated behaviour with regard to their overall perception of the service, level of satisfaction and intention to purchase from it again, which is fairly favourable.

Some of the aspects that online clients value most are those related to usability or the ease-of-use when making their purchases, as well as the possibility of contacting the company and the ease of returning products if there are any problems.

Other factors that online consumers mention are confidentiality and reliability in the service offered by this kind of establishment. They are users who are concerned by the security of their data and transactions; that the processes are carried out correctly and that any problems should be dealt with efficiently.

They particularly value confirmation that the purchasing process has been made properly, the ease of payment, the image of confidence and seriousness that the virtual supermarket gives and that it contains clear information about how to make the purchase. These aspects are closely related to concern about privacy and security as mentioned previously.

If we look at the behaviour of the segments, it is the younger clients (the first segment of our study) who demand a higher quality service. At the same time, it is the segment with greatest weight. They are also the clients with greatest experience in online shopping. They are used to shopping via a website and it is not difficult for them to change their supplier if they perceive greater added value in a competitor: they have a lower level of loyalty than the second segment. These results are in line with the segmentation work carried out using a varied type of factor to define behaviour and the attitude of online consumers (Keng et al., 2003).

The behaviour described should mean that the management of the supermarket is particularly careful to maintain and improve the standard of quality to retain these clients. Over time, these clients will migrate towards a type of behaviour that is less demanding and less loyal (the behaviour of the second segment). The investment made in its quality system must lead to a migration of clients from the first segment to the second one. At the same time, the efforts to maintain the standards in the four quality dimensions analysed will facilitate the entrance of new clients into the first segment. We should remember that the dimensions obtained (Efficiency, Availability of the System, Reliability and Privacy) confirm the structure followed by the E-S-Qual scale by Parasuraman et al. (2005), a scale which is a point of reference in studying the quality of service. 
The recommended strategy that is proposed in this case therefore is to satisfy the demands of the first segment to retain them and at the same time to attract other purchasers of the same profile. In this way, over time, these clients will migrate towards the second segment, which is those that remain with the company long-term and ensure a continuous turnover. In the six positioning maps, you can see a migration from the bottom left-hand square towards the top right-hand one.

The fact that a website has characteristics of its own due to the inherent reality of it being virtual, such as interactivity and connectivity, needs to be taken into account by any manager of this kind of business. In the same way, it should consider the way in which the contents and the purchasing processes and communication can be adapted to this interactive possibility. The interaction of the consumer will come in many ways: design of new products, development of communication strategy and differentiated marketing strategy or the innovation of the content (Hoffman et al., 1995). We should not forget the factors related to usability and attention to complaints that have been dealt with during this study.

To conclude this part, we would like to highlight the main limitations and possible lines of future research that arise from this piece of work. The main limitation of this study was the fact that it only studied the responses of clients of a virtual supermarket. This was due to the level of collaboration obtained with the management of the Plusfresc supermarket chain which facilitated this field of work. It would be interesting for future studies to extend the fields of work to other chains of establishments with a presence in the Internet which, at the same time, would provide us with an increase in the number of responses which would ensure a higher level of validity of the results. At the same time, we envisage not only analysing the food distribution, but also introducing ourselves into other sectors with a heavy online presence, such as travel agencies, as the product that they commercialise is usually among the first positions with regard to turnover in e-commerce in our country.

Another line of work that we have proposed, based on the factors obtained that define the quality of service offered by a virtual supermarket, as a future line of research, aims to create models of the relations that exist between the variables analysed and to analyse their influence on the final purchase of the product in this kind of establishment, using a model of structural equations for the analysis that allows us to measure the effects that exist between the constructs in a quantitative way.

\section{References}

Anderson, R., \& Srinivasan, S. (2003). E-satisfaction and e-loyalty: A contingency framework. Psychology \& Marketing, 20 (2), 123-138.

Bigné, E, Ruiz, C \& Andreu, L. (2004). Conceptualización del comportamiento del consumidor en los entornos virtuales. Un análisis cualitativo, Estudios sobre Consumo, 68, 9-20.

Boshoff, C. (2007). A psychometric assessment of E-S-QUAL: A scale to measure electronic service quality. Journal of Electronic Commerce Research, 8(1), 101-115.

Brown, M, Pope, N \& Voges, K. (2003). Buying or browsing? An exploration of shopping orientations and virtual purchase intention, European Journal of Marketing, 37 (11/12), 1666-1684.

Celestino, A \& Borja, A. (2005). Internet como canal de distribución adicional en el sector de la distribución alimentaria. Estado de la Cuestión. Anales de Economía Aplicada 2005. 19th Annual Meeting Asepelt-España (CD-ROM). Badajoz.

CMT (Telecommunications Market Committee). (2010). Informe sobre el comercio electrónico en España a través de entidades de medios de pago (IV Trimestre 2009). [Online] Available: http://www.cmt.es/

Cristóbal Fransi, E. (2006). El merchandising en el establecimiento virtual: una aproximación al diseño y la usabilidad. ESIC MARKET. Economic and Business Journal (Revista Internacional de Economía y Empresa), $123,115-164$.

Cristóbal, E \& Marimon, F. (2007). A study of e-retailing management: analysing the expectations and perceptions of Spanish consumers. International Journal of Consumer Studies, 31, 613-622.

Donthu, N., and Garcia, A. (1999). The internet shopper. Journal of Advertising Research, 39 (3), 52-58.

Flavián, C and Gurrea, R. (2004). El estudio del comportamiento del consumidor en un entorno virtual. Estudios sobre Consumo, 68, 41-52.

Fuentes, M., Gil, I., Berenguer, G., and Moliner, B. (2010). Measuring the antecedents of e-loyalty and the effect of switching costs on website. The Service Industries Journal, 30 (11), 1837-1852.

Hoffman, D. L., Novak, T. P., and Chatterjee, P. (1995). Commercial Scenarios for the Web: Opportunities and 
Challenges. Journal of Computer Mediated Communication, 1 (3), 23-45.

Huang, L. (2008). Exploring the determinants of E-loyalty among travel agencies. The Service Industries Journal, 28 (2), 239-254.

Internet World Stats. (2010). World Internet Users and Population Statistics. [Online] Available: http://www.internetworldstats.com/

Keng, K., Tang, Y., \& Ghose, S. (2003). Typology of online shoppers. Journal of Consumer Marketing, 20 (2), 139-156.

Li, H. R., Cheng, K., and Russell, M. G. (1999). The Impact of Perceived Channel Utilities, Shopping Orientations, and Demographics on the Consumer's Online Buying Behavior. Journal of Computer Mediated Communication, 5(2), 85-103.

Lin, W. B. (2010). Service recovery expectation model - from the perspectives of consumers. The Service Industries Journal, 30 (6), 873-889.

Lohse, G. L., \& Spiller, P. (1999). Internet retail store design: How the user interface influences traffic and sales. Journal of Computer Mediated Communication, 5 (2).

Lohse, G. L., and Spiller, P. (1998). Electronic Shopping: The effect of customer interfaces on traffic and sales. Communications of the ACM, 41 (7), 81-87.

Mandel, N., and Johnson, E. (1999). Constructing Preferences Online: Can Web Pages Change What You Want? Working Paper, University of Pennsylvania. 1-37.

Manfreda, K. L., Bosnjak, M., Berzelak, J., Haas, I., and Vehovar, V. (2008). Web Surveys versus Other Survey Modes - A Meta-Analysis Comparing Response Rates. International Journal of Market Research, 50 (1), 79-104.

Marimon, F., Vidgen, R., Barnes, S., and Cristobal, E. (2010). Purchasing behaviour in an online supermarket: the applicability of E-S-QUAL. International Journal of Market Research, 52 (1), 111-129.

Martínez, M., Saco, M., and Fernández, R. (2008). Estudio comparativo de los supermercados online españoles: análisis del contenido de los sitios webs. Esic Market, 131, 97-146.

Menon, S., and Kahn, B. (1997). Cross-Category Effect of stimulation on the shopping experience: An application to Internet shopping. Working Paper 97-006. The Warton School. University of Pennsylvania.

Parasuraman, A., Zeithaml, V. A., \& Malhotra, A. (2005). E-S-Qual: A Multiple-Item Scales for Assessing Electronic Service Quality. Journal of Service Research, 7 (3), 213-233.

Paypal/Comscore. (2008). PayPal Survey Reveals Consumers' Top Reasons for Abandoning Online Purchases. [Online] Available: https://www.paypal-media.com/releasedetail.cfm?ReleaseID=312548.

Quader, M. S., and Quader, M. R. (2008). The utilization of e-commerce by traditional supermarkets in the UK through strategic alliances with internet based companies. Journal of Services Research, 8 (1), 177-211.

RED.ES (2009). Comercio electrónico B2C 2009. [Online] Available: http://www.red.es.

Ribbink, D., Van Riel, A., Liljander, V., and Streukens, S. (2004). Comfort your online customer: quality, trust and loyalty on the Internet. Managing Service Quality, 14(6), 446-456.

Rodríguez Ardura, I. (2008). Marketing.com: Marketing y comercio electrónico en la sociedad de la información. Edición Pirámide. Madrid.

Rohm, A., Swaminathan, V. (2004). A typology of online shoppers based on shopping motivations. Journal of Business Research, 57, 748-757.

Ruiz Mafé, C., and Sanz Blas, S. (2005). Segmentación del comprador a distancia: un análisis de los medios Internet y televisión. Investigaciones Europeas de Dirección y Economía de la Empresa. 11 (2), 163-182.

Ruiz Mafé, C., and Sanz Blas, S. (2006). Perfil, comportamiento y satisfacción en Internet como variables de segmentación de los compradores virtuales. Estudios sobre Consumo, 78, 9-20.

Saco, M., Fernández, R., and Martínez, M. (2008). Supermercados.com: Marketing para los supermercados virtuales. ESIC Editorial.

Sigala, M., and Sakellaridis, O. (2004). Web users' cultural profiles and e-service quality: internationalization implications for tourism websites. Information Technology and Tourism, 7 (1), 13-22. 
Srinivasan, S., Anderson, R., and Ponnavolu, K. (2002). Customer loyalty in e-commerce: An exploration of its antecedents and consequences. Journal of Retailing, 78(1), 41-50.

Swaminathan, V., Lepkowska-White, E., and Bharat, P. R. (1999). Browsers or Buyers in Cyberspace? An Investigation of Factors Influencing Electronic Exchange. Journal of Computer Mediated Communication, 5 (2).

Swinyard, W., and Smith, S. (2003). Why people don't shop online: A lifestyle study of the Internet consumer. Psychology \& Marketing, 20 (7), 567-597.

TNS-Consumer. (2008). Barómetro de la Distribución (2008). [Online] Available: http://www.tns-global.es/docs/docs_soluciones_140.pdf.

Van Riel, A., Liljander, V., and Jurriëns, P. (2001). Exploring consumer evaluations of e-services: a portal site. International Journal of Service Industry Management, 12 (4), 359-377.

Vrechopoulos, A., Siomkos, G., and Doukidis, G. (2001). Internet shopping adoption by Greek consumers. European Journal of Innovation Management, 4 (3), 142-152.

Yang, X., Zafar, U. A., Morry, G., Goh Sock, B., Tham Su, M., and Lim, L. (2003). Consumer Preferences for Commercial Website design: an Asia-Pacific perspective. Journal of Consumer Marketing, 20 (1), 10-27.

Table 1. Merchandising Factors in Physical and Virtual Environments

\begin{tabular}{|c|c|c|}
\hline & $\begin{array}{l}\text { Conventional Merchandising } \\
\text { Factors } \\
\end{array}$ & $\begin{array}{l}\text { Merchandising } \\
\text { Factors in A Virtual Environment }\end{array}$ \\
\hline \multirow{4}{*}{$\begin{array}{l}\text { Presentation } \\
\text { merchandising: } \\
\text { exterior layout of the } \\
\text { establishment }\end{array}$} & Sign & Domain name \\
\hline & Entrance to the establishment & $\begin{array}{l}\text { Links to the establishment from } \\
\text { information intermediaries and other } \\
\text { virtual offices }\end{array}$ \\
\hline & Façade & Home page of the website \\
\hline & Shop window & Attractive products on the home page \\
\hline \multirow{3}{*}{$\begin{array}{l}\text { Presentation } \\
\text { merchandising: } \\
\text { interior layout of the } \\
\text { establishment }\end{array}$} & $\begin{array}{l}\text { Plan and internal layout of the } \\
\text { establishment (direction of the } \\
\text { circulation, placing of the sections, } \\
\text { cashiers, etc.). }\end{array}$ & $\begin{array}{l}\text { Structure of the website, navigation } \\
\text { routes, search tools and recommendation. }\end{array}$ \\
\hline & $\begin{array}{l}\text { Layout and presentation of the } \\
\text { assortment (design of the linear space } \\
\text { and presentation of the products in the } \\
\text { linear space) }\end{array}$ & Design of the interface of the E-catalogue \\
\hline & Animation of the point-of-sale & $\begin{array}{l}\text { Animation techniques, advertising in the } \\
\text { point-of-sale and management of virtual } \\
\text { communities }\end{array}$ \\
\hline \multirow{2}{*}{$\begin{array}{l}\text { Merchandising } \\
\text { management }\end{array}$} & $\begin{array}{l}\text { Selection and analysis of the } \\
\text { assortment }\end{array}$ & $\begin{array}{l}\text { Selection and analysis of the components } \\
\text { of the catalogue }\end{array}$ \\
\hline & Management of the linear space & Organisation of the E-catalogue \\
\hline
\end{tabular}

Source: Rodríguez Ardura (2008) 
Table 2. Advantages and Inconveniences of the Internet Channel in the Food Distribution Sector

\begin{tabular}{|c|c|}
\hline Advantages/Potentials & Inconveniences \\
\hline $\begin{array}{l}\text { Overall presence / expansion of the demand } \\
\text { Customising the offer and contents/quality of the } \\
\text { service } \\
\text { Reduction of certain kinds of costs } \\
\text { Continually updated information } \\
\text { Synergies between different sales channels } \\
\text { Fast access to a great amount of information/greater } \\
\text { facility to carry out comparisons } \\
\text { Greater convenience, saving time and effort } \\
\text { Accessibility to a greater number of products } \\
\text { Fresh food }\end{array}$ & $\begin{array}{l}\text { The digital breach } \\
\text { Increase of the competition } \\
\text { Lack of security } \\
\text { Need to restructure the internal functioning of the } \\
\text { company } \\
\text { Considerable investment required by the company } \\
\text { Facing a culture and habits that are not very common } \\
\text { in distance purchasing }\end{array}$ \\
\hline
\end{tabular}

Source: Celestino and Borja (2005)

Table 3. Wilcoxon Mann-Whitney Test on Comparison of Averages between Variables

\begin{tabular}{|l|c|c|c|}
\hline & Perceived value & Response to problems & Satisfaction \\
\hline Mann-Whitney U & 879.500 & 194.500 & $1,083.000$ \\
\hline Wilcoxon W & $7,782.500$ & $1,734.500$ & $7,986.000$ \\
\hline Z & -6.167 & -1.863 & -5.471 \\
\hline Asymp. sig (bilateral) & $.000(*)$ & .062 & $.000\left(^{*}\right)$ \\
\hline
\end{tabular}

(*) Differences of significant averages with a significance of 0.05

Table 4. Rotated Component Matrix

\begin{tabular}{|l|c|c|c|c|}
\hline & Factor 1 & Factor 2 & Factor 3 & Factor 4 \\
\hline The information on the website is well organised & $\mathbf{. 8 3 5}$ & .146 & .106 & .117 \\
\hline It allows me to complete the purchasing process quickly & $\mathbf{. 7 0 6}$ & .372 & -.047 & .040 \\
\hline It is well organised & $\mathbf{. 6 8 6}$ & .174 & .342 & .183 \\
\hline It is easy to access any section of the website & $\mathbf{. 6 4 3}$ & .292 & .025 & .085 \\
\hline This website transmits a purchasing environment quickly & $\mathbf{. 6 2 6}$ & .336 & .333 & .044 \\
\hline It is easy to use & $\mathbf{. 5 2 9}$ & .355 & .288 & .235 \\
\hline It is easy to find what I am looking for & $\mathbf{. 5 0 1}$ & -.101 & .397 & -.065 \\
\hline They are sincere with their offers & .458 & .167 & .280 & .133 \\
\hline The website downloads and functions immediately & .225 & $\mathbf{. 8 3 2}$ & .051 & .090 \\
\hline It does not block & .147 & $\mathbf{. 8 2 5}$ & -.066 & .062 \\
\hline The pages download rapidly & .280 & $\mathbf{. 6 8 7}$ & .092 & .208 \\
\hline It is always available to be able to purchase & .378 & $\mathbf{. 6 2 6}$ & .049 & .017 \\
\hline The pages do not block after I have entered my order & .231 & $\mathbf{. 5 4 7}$ & .397 & .046 \\
\hline The timeslots that suit me are usually available & .024 & $\mathbf{. 5 2 7}$ & .501 & .099 \\
\hline Delivery of orders when promised & .110 & .082 & $\mathbf{. 8 1 0}$ & .058 \\
\hline Delivery of products ordered in correct condition & .132 & -.045 & $\mathbf{. 7 4 3}$ & -.004 \\
\hline Availability of the products that the company claims to have & .266 & -.002 & $\mathbf{. 6 5 0}$ & .064 \\
available & & & & \\
\hline The timeslots for home delivery are suitable & .104 & .346 & $\mathbf{. 5 5 9}$ & .053 \\
\hline They do not share my personal data with other websites & .072 & .138 & -.025 & $\mathbf{. 8 9 7}$ \\
\hline They protect the information about my credit card & .079 & .114 & -.013 & $\mathbf{. 8 9 7}$ \\
\hline They protect the information about my purchasing behaviour & .213 & .047 & .227 & $\mathbf{. 8 3 9}$ \\
\hline
\end{tabular}


Table 5. Wilcoxon Mann-Whitney test on comparison of averages of the quality dimensions.

\begin{tabular}{|l|c|c|c|c|}
\hline & Efficiency & Availability & Reliability & Privacy \\
\hline Mann-Whitney U & 904.500 & $1,189.000$ & $1,410.500$ & $1,632.500$ \\
\hline Wilcoxon W & $7,807.500$ & $8,092.000$ & $8,313.50$ & $8,535.500$ \\
\hline Z & -6.096 & -4.985 & -4.129 & -3.361 \\
\hline Asymp. sig (bilateral) & .000 & .000 & .000 & .001 \\
\hline
\end{tabular}

(*) Differences of significant averages with the significance of 0.05

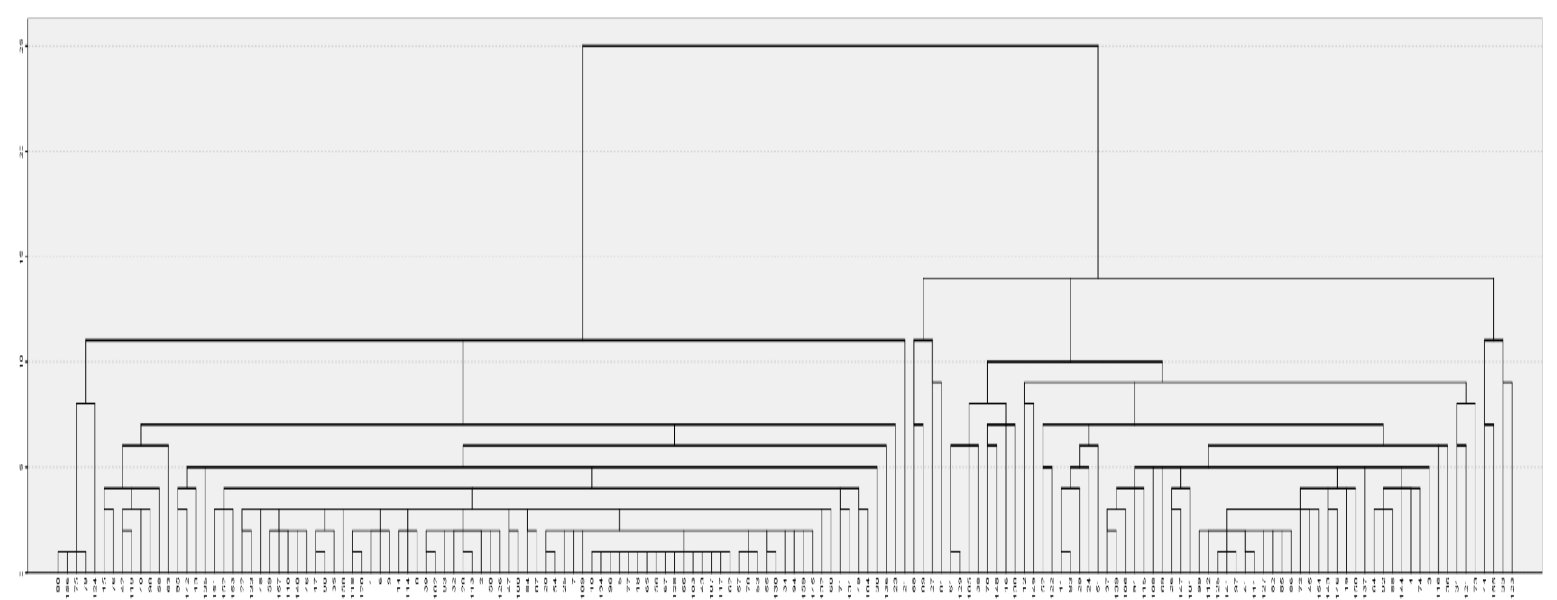

Figure 1. Hierarchical Analysis

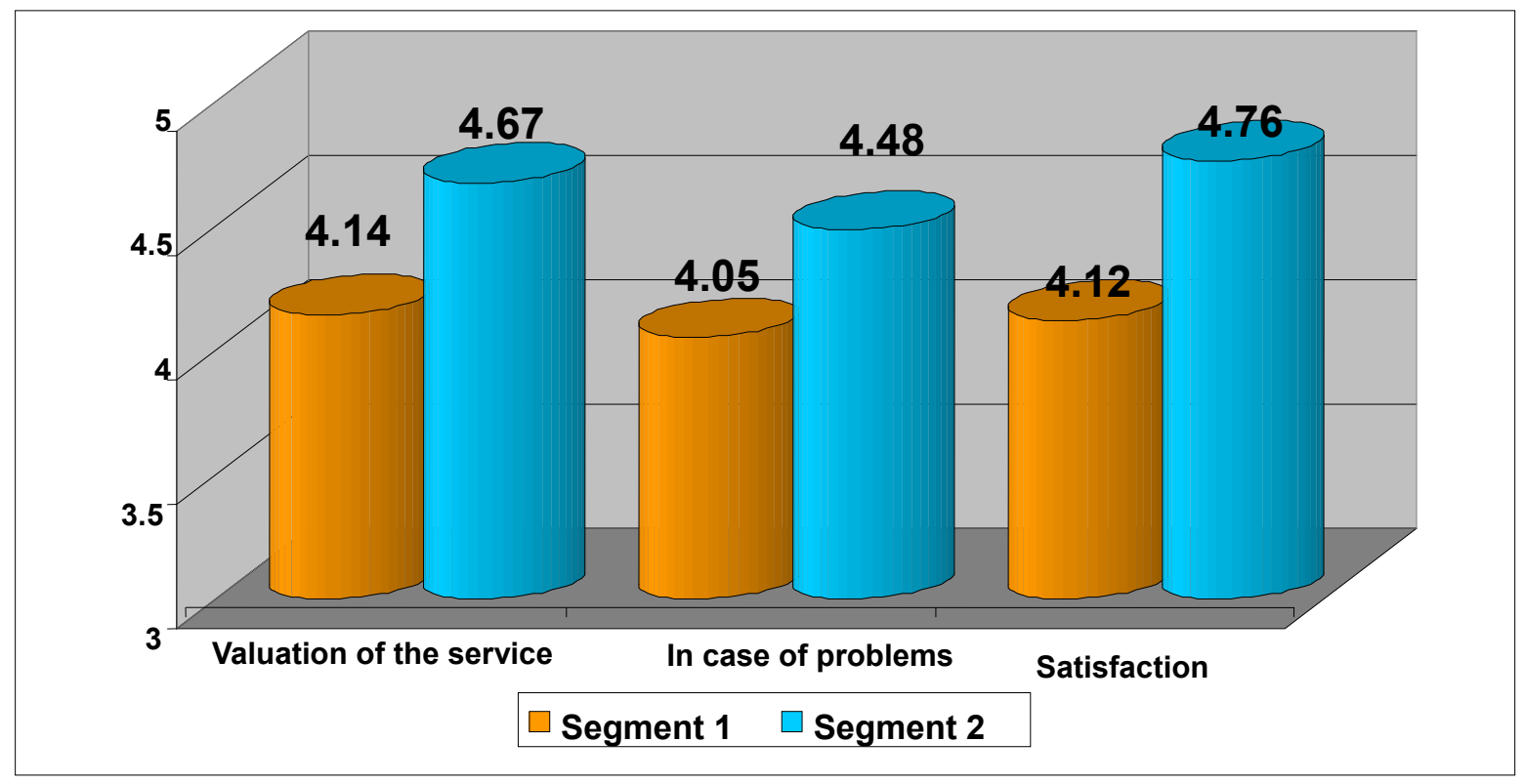

Figure 2. Average Marks per Segment of the Service Received 


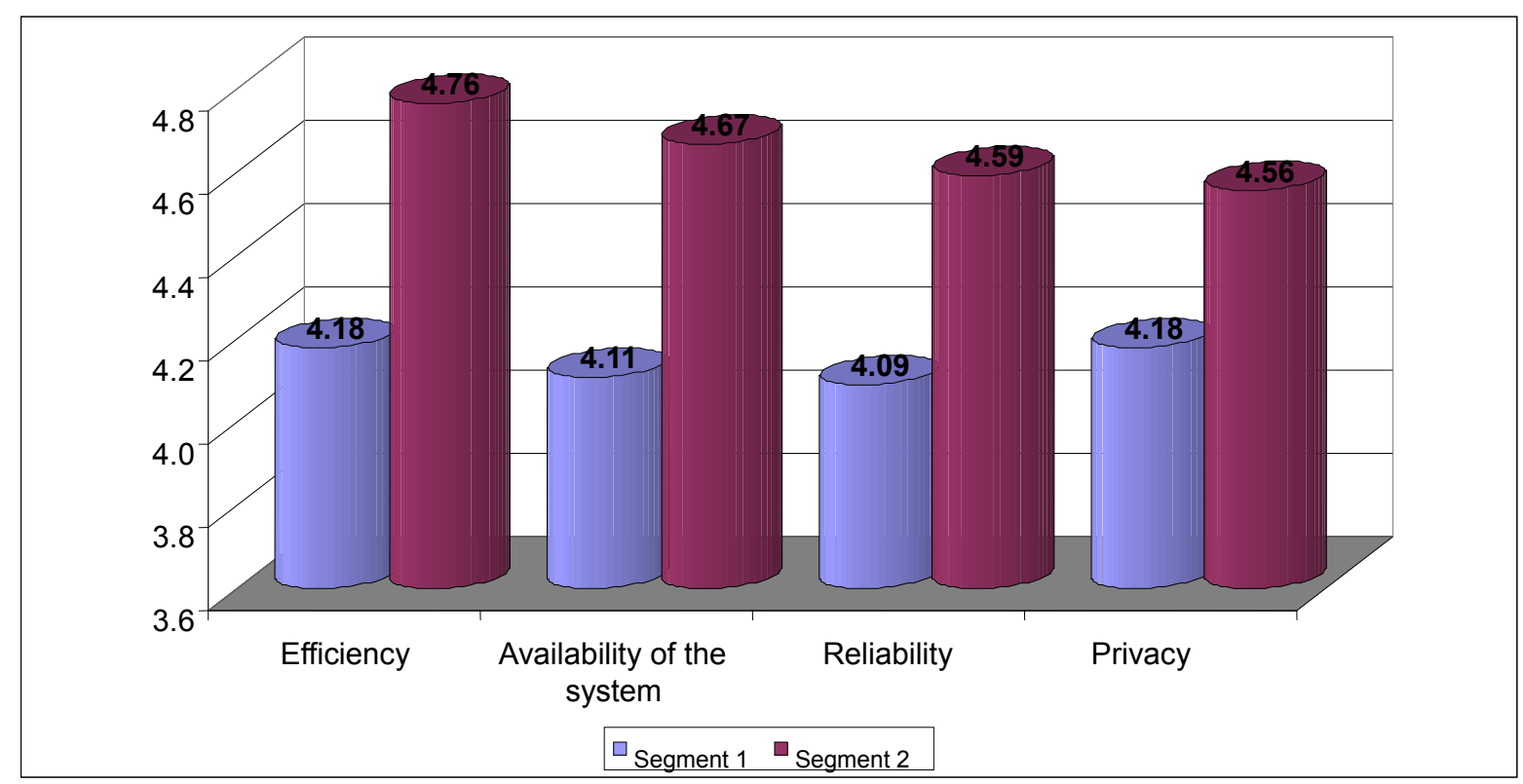

Figure 3. Rating of the Factors that Define the Quality of the Service when Grouped by Segments
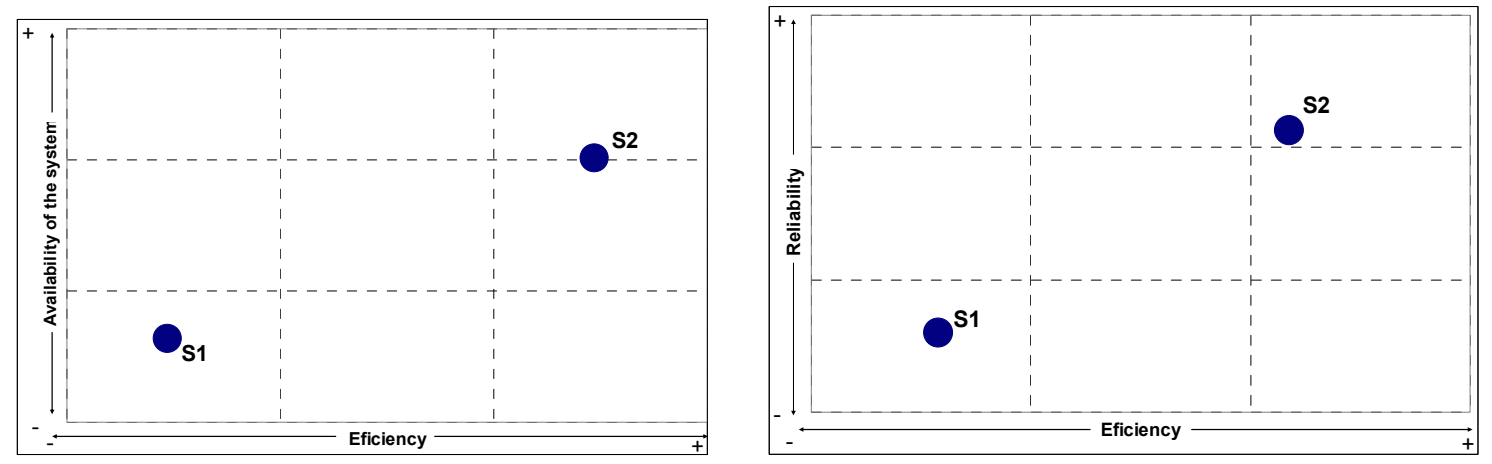

Figure 4. Positioning Factors Efficiency with Availability of System and Reliability
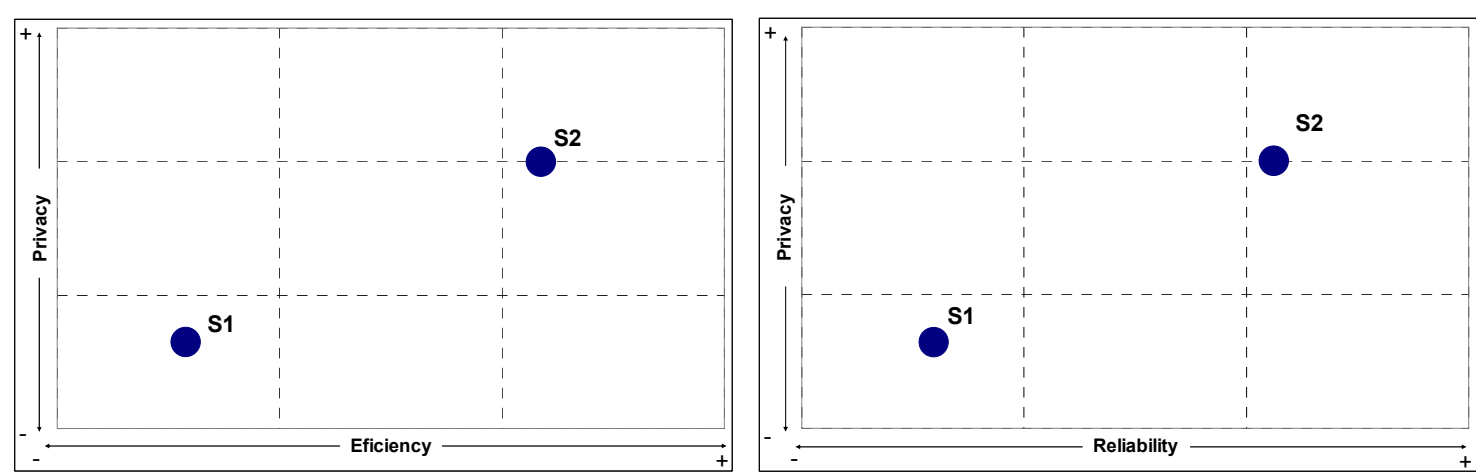

Figure 5. Positioning Factors Efficiency with Privacy and Factor Reliability with Privacy 

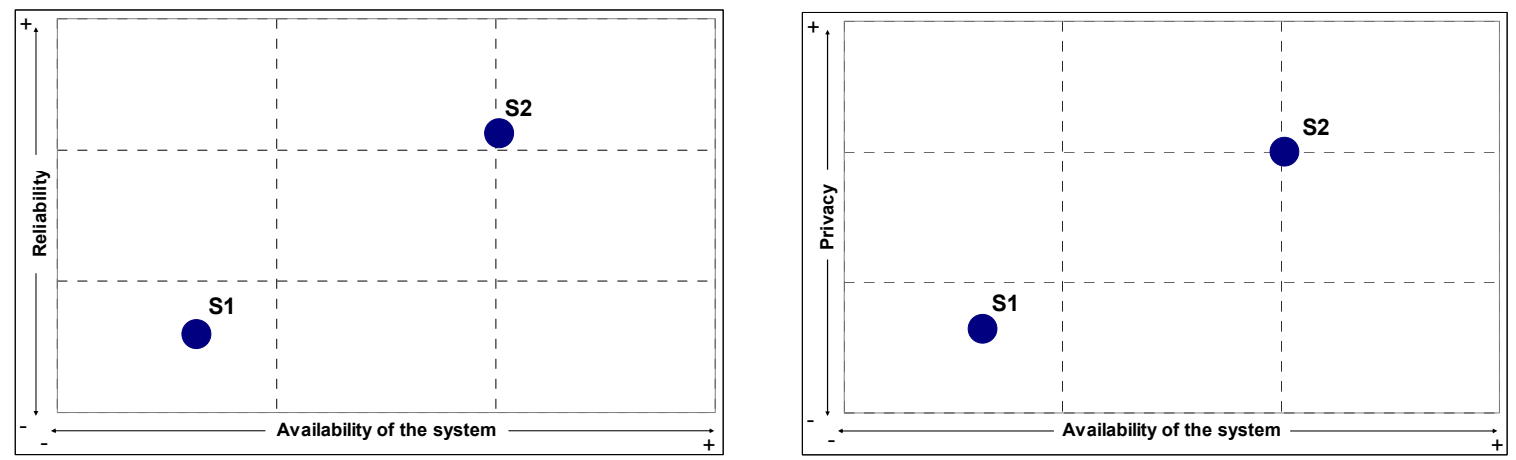

Figure 6. Positioning Factors Availability of System with Reliability and Privacy 